\title{
Ecological sensitivity: a biospheric view of climate change
}

\author{
Jon C. Bergengren • Duane E. Waliser • Yuk L. Yung
}

Received: 29 January 2009 / Accepted: 2 July 2010 / Published online: 22 July 2011

(C) The Author(s) 2011. This article is published with open access at Springerlink.com

\begin{abstract}
Climate change is often characterized in terms of climate sensitivity, the globally averaged temperature rise associated with a doubling of the atmospheric $\mathrm{CO}_{2}$ (equivalent) concentration. In this study, we develop and apply two new ecological sensitivity metrics, analogs of climate sensitivity, to investigate the potential degree of plant community changes over the next three centuries. We use ten climate simulations from the Intergovernmental Panel on Climate Change Fourth Assessment Report, with climate sensitivities from $2-4^{\circ} \mathrm{C}$. The concept of climate sensitivity depends upon the continuous nature of the temperature field across the Earth's surface. For this research, the bridge between climate change and biospheric change predictions is provided by the Equilibrium Vegetation Ecology model (EVE), which simulates a continuous description of the Earth's terrestrial plant communities as a function of climate. The ecosensitivity metrics applied to the results of EVE simulations at the end of the twenty-first century result in $49 \%$ of the Earth's land surface area undergoing plant community changes and $37 \%$ of the world's terrestrial ecosystems undergoing biome-scale changes. EVE is an equilibrium model, and, although rates of ecological change are not addressed, the resultant ecological sensitivity projections provide an estimate of the degree of species turnover that must occur for ecosystems to be in equilibrium with local climates. Regardless of equilibrium timescales, the new metrics highlight the Earth's degree of ecological sensitivity while identifying ecological "hotspots" in the terrestrial biosphere's response to projected climate changes over the next three centuries.
\end{abstract}

This paper is dedicated to my great friend and mentor Steve Schneider. - J. C. Bergengren

J. C. Bergengren $(\varangle)$ · Y. L. Yung

Division of Geological and Planetary Sciences, Caltech, Pasadena, CA, USA

e-mail: globalecologist@gmail.com

D. E. Waliser

Water and Carbon Cycles Group, Jet Propulsion Laboratory, Pasadena, CA, USA 


\section{Introduction}

Human activities are an increasingly important component of the Earth system. The potential impact of human activity on climate change is often numerically described in terms of climate sensitivity, usually defined as the globally and annually averaged change in the Earth's $(2 \mathrm{~m})$ surface temperature in response to a $\mathrm{CO}_{2}$ (equivalent) doubling (Schneider 2001; Senior and Mitchell 2000; Washington and Meehl 1989). After decades of research and continually improving climate models, the consensus is that this doubling of radiatively active greenhouse gases (GHGs) from anthropogenic sources is expected to cause a global $2-4^{\circ} \mathrm{C}$ temperature rise by the end of the twenty-first century (Hansen et al. 2000; IPCC 2007; Schneider 2004). With the use of this climate sensitivity metric comes the understanding that the underlying geographic patterns of projected temperature, precipitation, snow/ice and other physical changes are very complex, with areas of the world becoming warmer or colder, drier or wetter, etc.

It is the presence of life on Earth, including ourselves, that elevates observed and predicted aspects of climate change to the forefront of scientific research and political dialogues. What if we adopted a biospheric view of anthropogenic climate changewhat would we see? Plant community composition and dynamics evolve in response to climate change, creating the need for biospheric analogs to climate change and climate sensitivity. For example, it is well known that climate and climate change, combined with topography, soil types, and disturbance regimes, are central drivers of the state and trajectory of plant geography (Box 1996; Delcourt et al. 1983; McCarty 2001). Ultimately, plant species must "migrate" in response to climate change, as they can only survive, compete, and reproduce within the range of climates to which they are evolutionarily and physiologically adapted. Plant species migrations result in changes in plant community compositions. Combined with possible consequent alterations of ecosystem functioning, plant community changes could be disruptive to the stability of populations of endangered plant and animal species, and could have significant impacts on the Earth's water, carbon, biogeochemical, and energy cycles. Potential ecosystem responses to climate change scenarios have usually been characterized by ecologists in terms of regional plant community transitions or changes (mostly losses) in plant and animal biodiversity for different areas of interest (Lovejoy and Hannah 2005; Sala et al. 2000; Thomas et al. 2004).

In order to quantify the response of the terrestrial biosphere to climate change and explore the relationships between projected climate sensitivity and ecological response, we develop and apply two new ecological sensitivity or ecosensitivity metrics. These metrics provide the means to investigate global change from a biospheric point of view by transforming complex projected terrestrial ecosystem changes resulting from model-predicted climate changes into simple scalars that vary across the landscape like climate variables. In Section 2, we describe the ecological model used to transform climate change into ecological change, the climate change model simulations that the ecological model is applied to, and the two ecological sensitivity metrics. In Section 3, we describe the model-projected climate changes in terms of ecological sensitivity. In Section 4, we discuss the relations between ecological sensitivity and climate sensitivity. In Section 5, we provide a summary and concluding remarks. 


\section{Experimental design and methodology}

\subsection{The IPCC climate change scenarios and GCM simulations}

The United Nations Intergovernmental Panel on Climate Change (IPCC) commissioned a Special Report on Emission Scenarios (SRES) that describes a spectrum of possible future conditions generated by the evolution of human society, including prescribed levels of atmospheric greenhouse gases, such as carbon dioxide and methane (IPCC 2007). The intermediate IPCC SRES A1B scenario calls for climate simulations of the twentieth and twenty-first centuries, applying a transient doubling of tropospheric $\mathrm{CO}_{2}$ (equivalent) over the twenty-first century from 360 to 720 parts per million (ppm), with the option to continue the simulation at constant elevated $\mathrm{CO}_{2}$ levels to the end of the twenty-second or twenty-third century.

In this study, we explore the results from 10 global climate model (GCM) simulations of the IPCC Fourth Assessment intermediate SRES A1B scenario performed by eight research centers. Monthly mean temperature, precipitation, and relative humidity fields are derived from the final 30 model years for each century and are used to create maps of climate and climate change, assess climate sensitivity in response to the $\mathrm{CO}_{2}$ doubling after one, two, and three centuries of climate change, and to generate plant community predictions and ecological sensitivity results.

For intercomparison, all monthly mean model climate fields were converted to a $1^{\circ} \times 1^{\circ}$ (latitude $\times$ longitude) grid using bilinear interpolation. The $10 \mathrm{GCM}$ simulations were divided into thirty-two 100-year segments: 10 each for the twentieth and twenty-first centuries, seven for the twenty-second century, and five for the twenty-third century, depending upon the duration of each simulation. In addition, the interpolated 30-year mean climatologies were averaged across all of the GCM simulations available for each of the four centuries, creating a total of thirty-six 100year simulation segments.

\subsection{The Equilibrium Vegetation Ecology model}

The bridge between climate change projections and an ecological complement to climate sensitivity is the Equilibrium Vegetation Ecology model (EVE), which provides the requisite continuous mathematical description of the state of terrestrial vegetation as a function of climate (Bergengren et al. 2001). Based upon ecological principles, EVE transforms monthly mean climate into an equilibrium prediction of plant community structure, defined by the fractional covers of 110 plant life forms for each landscape point characterized by the climate data.

The EVE model has been successfully used to explore biosphere-climate interactions for both paleoclimate scenarios (DeConto et al. 1998; DeConto et al. 1999a, b; Pollard et al. 1998) and future climate scenarios (Bergengren et al. 2001). To simplify the analysis of EVE simulations, the 110 life form maps can be transformed into plant community maps that use either five or 12 biomes to describe the vegetated landscape. Ten examples of the 110 global life form maps and the five-biome map for an EVE simulation driven by 1950-1980 monthly mean climate data can be seen in Figs. 1 and 2 (adapted from Bergengren et al. 2001). Note that each of 


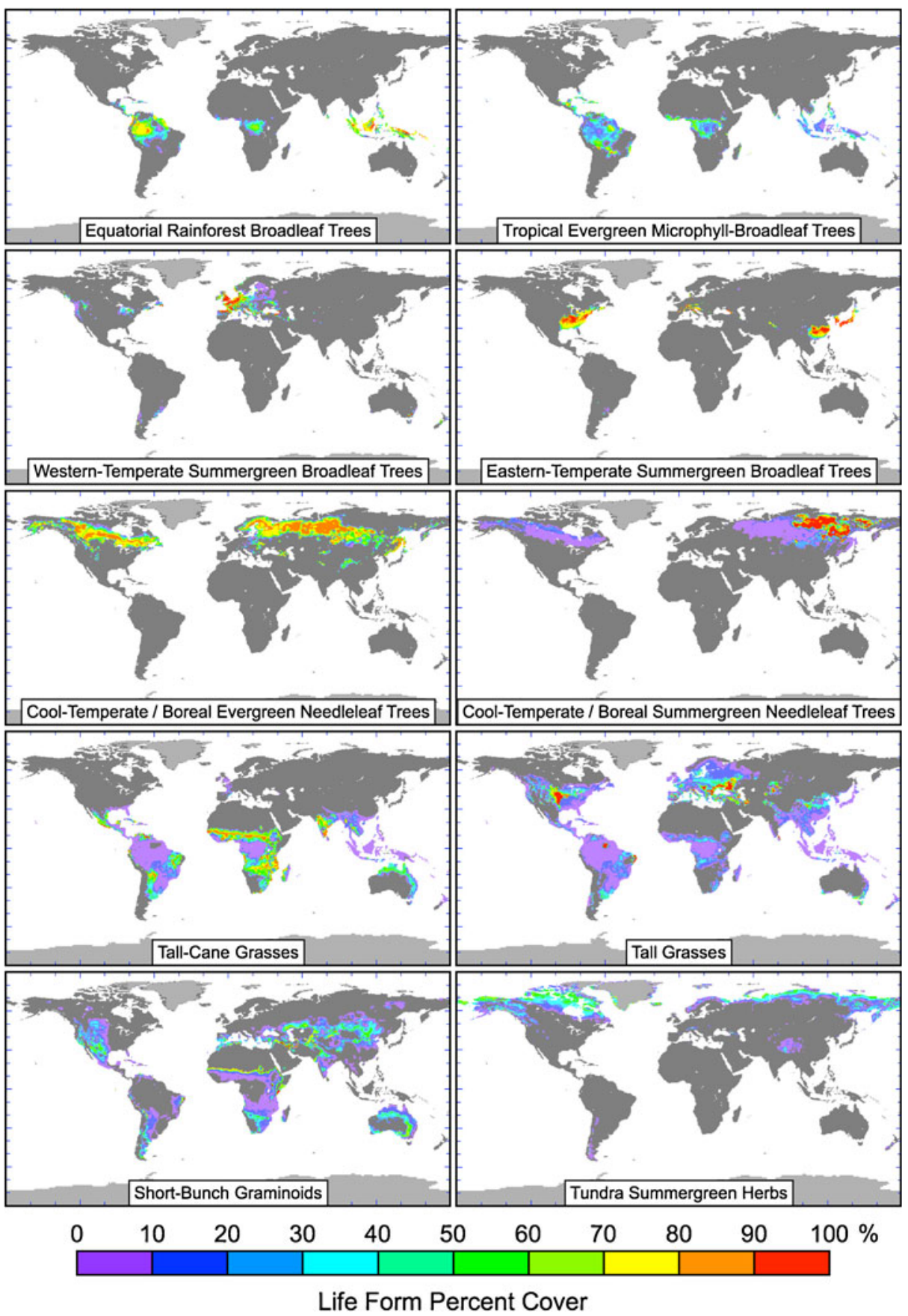

Fig. 1 Ten examples of EVE's 110 global life form fractional cover maps created by driving the EVE model with 1950-1980 monthly mean climate data 


\section{EVE Control Simulation: $20^{\text {th }}$ Century Biomes}

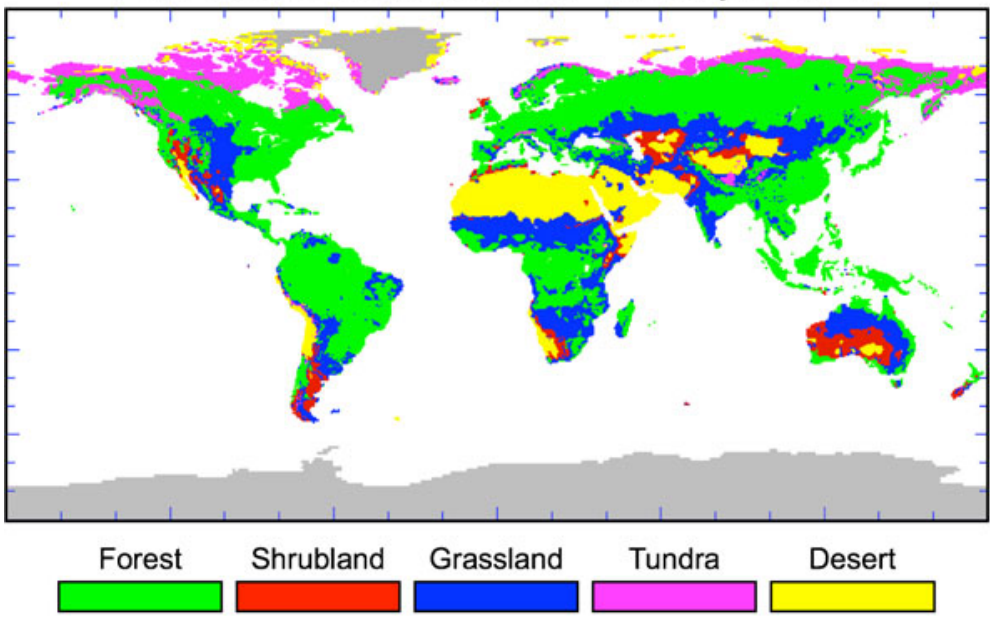

Equilibrium Vegetation Ecology Model Biomes

Fig. 2 A simple 5-biome map derived from EVE's 110 life form fractional cover maps associated with an EVE simulation driven by 1950-1980 monthly mean climate data

the 110 life form maps is a continuously varying scalar field that captures some of the heterogeneities of the natural world while providing the mathematical basis for deriving our ecological sensitivity metrics.

\subsection{The new ecological sensitivity metrics}

The concept of climate sensitivity depends upon the continuous nature of the temperature field across the Earth's surface, which allows for the prediction of temperature changes and the averaging of these changes across the globe and the seasons. In contrast, classification schemes of the world's vegetation are usually discontinuous like the biome map in Fig. 2, and therefore do not easily support an analogous assessment of ecological change.

Here we describe and apply two new metrics that are easy to think about in terms of observable changes of the response of natural terrestrial ecosystems to climate change, which we call Ecological Sensitivity 1 and 2 (or ES1 and ES2). ES1 is the fraction of the landscape area that experiences a life form change in any of the three plant canopy levels of EVE. For the second metric (ES2), life forms are divided into five groups that are associated with the system of very simple biomes shown in Fig. 2: forest, shrubland, grassland, tundra, and desert. The ES2 metric is the fraction of the landscape that transitions, in at least one of the plant canopy levels, from one biomeassociated life form to another. ES1, for example, includes change from one type of tree to another type of tree, while the biome probably remains forest, whereas ES2 only includes ecologically dramatic changes, such as from some type of tree to a grass life form. 
Ecological Sensitivity 1 is a function of the degree of life form turnover in the three canopy levels of a plant community:

$$
\begin{aligned}
E S 1 & =A+(1-A) B+(1-(A+(1-A) B)) C \\
& =1-(1-A)(1-B)(1-C),
\end{aligned}
$$

where $\mathrm{A}, \mathrm{B}$, and $\mathrm{C}$ are the fractions of the landscape undergoing change in each of EVE's three canopy layers (more or less the tree, shrub, and grass layers). Plant canopy changes are defined as the sum of the absolute values of the areas lost or gained by all of the life forms within each canopy level, minus an estimate of the random overlaps of changes occurring within and between the three canopy layers. Some life forms replace others; some recede leaving new gaps, while others colonize previous light gaps. ES2 has the identical functional form as ES1-the only difference is in the calculations of $\mathrm{A}, \mathrm{B}$, and C. Whereas for ES1, there are 110 plant life forms that can undergo transitions that add to the three sums of plant cover changes, for ES2, there are effectively only five vegetation types (see above) that can undergo transitions. ES2, therefore, is intrinsically a less sensitive metric than ES1, representing much greater degrees of transformation in plant community compositions.

Ecological sensitivity maps were created from the life form fractional cover maps generated by the EVE-simulated response of terrestrial vegetation to the 36 IPCC SRES A1B-derived single century climate simulations. A noteworthy difference in the use of the EVE model in this research relative to previous GCM-related efforts is that this study does not require bias correction to the GCM-generated climate to drive EVE. In GCM-related studies in the past, the EVE model was driven by monthly mean model climate anomalies added to the (observed 1950-1980 monthly mean) control climate in order to filter out the GCM's systematic biases. The current generation of coupled GCMs has progressed enough to use the unfiltered monthly mean model climate output directly.

\section{Results}

\subsection{Climate change}

The projected response of the Earth's monthly mean climate to the IPCC SRES A1B trace gas forcing scenario can be seen in Figs. 3, 4, 5 and 6. Each figure consists of January and July global 2-m (above the Earth's surface) air temperature and precipitation maps. The simulated climatic means for the twentieth century are shown in Fig. 3, while Figs. 4, 5 and 6 display climate change projections for the twenty-first, twenty-second, and twenty-third centuries.

These climate maps show the monthly mean climates for the 30-year equilibrium period at the end of each century, averaged across all the GCM simulations that include each century. The twentieth and twenty-first century results in Figs. 3 and 4 are from all 10 GCM simulations, while the twenty-second century results in Fig. 5 summarize the output from the seven 300-year simulations, and the twentythird century results in Fig. 6 are derived from the five climate simulations that were run for 400 years. (For details, see Table 1 below.) The climate change maps for the latter three centuries show the differences between the average 

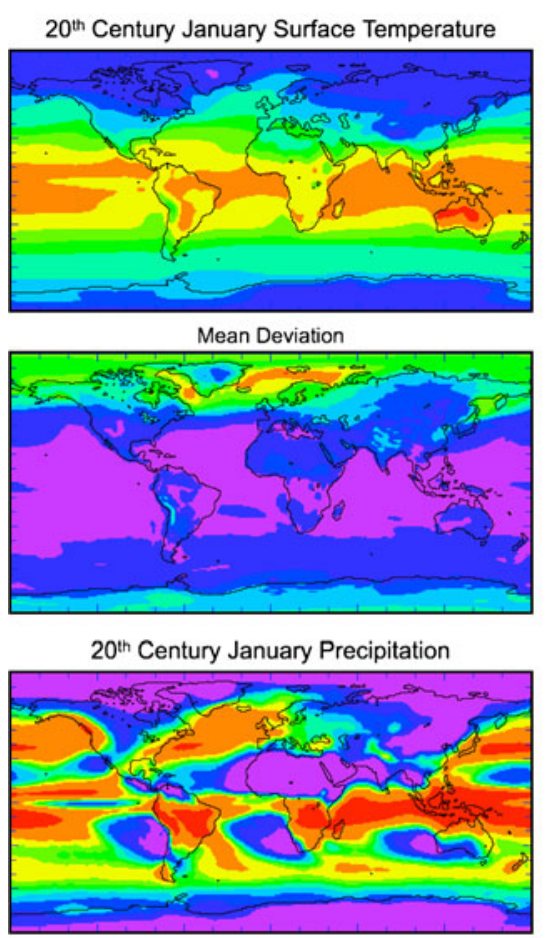

Mean Deviation

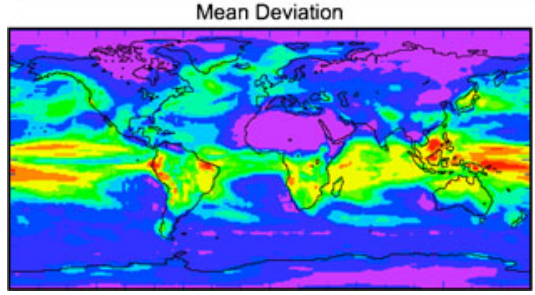

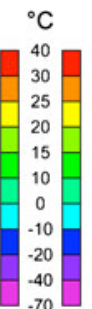

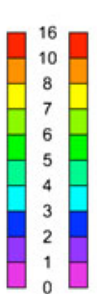

$\mathrm{mm}$
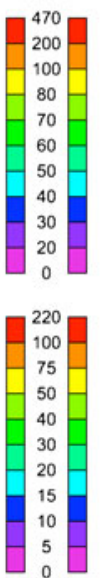

$20^{\text {th }}$ Century July Surface Temperature

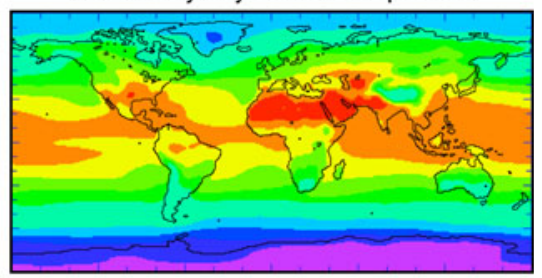

Mean Deviation

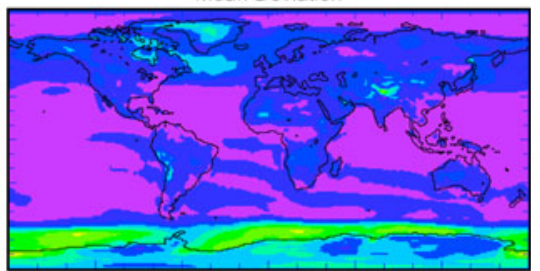

$20^{\text {th }}$ Century July Precipitation

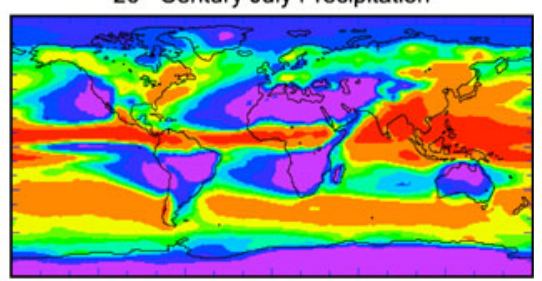

Mean Deviation

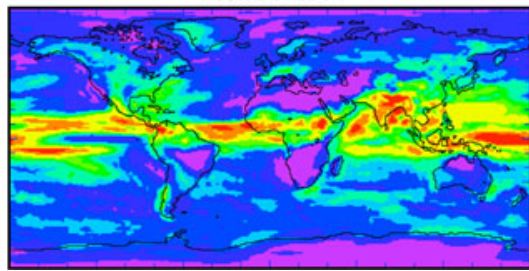

Fig. 3 Twentieth century three-decade mean (1971-2000) January and July surface temperature and precipitation and mean deviations, averaged across all $10 \mathrm{GCM}$ simulations

climate conditions of all the GCM simulations that included each particular century and the average climatic conditions from the same group's twentieth century simulations.

Mean deviation maps, which show the average of the absolute deviations from the mean, accompany each of the global climate and ecological sensitivity maps in this paper in order to show the degree of agreement for model results from each century. The mean deviation is used rather than the standard deviation that is better suited for larger data ensembles that follow a roughly normal distribution, which is unlikely to apply to the geographic and seasonal climate patterns of such a small group of climate simulations. In addition, there is a certain intuitive clarity associated with the linearity of these maps of the "mean deviation from the mean".

The twentieth century temperature and precipitation fields in Fig. 3 are fairly consistent across the models, with the greatest temperature mean deviations at high latitudes in the winter and the greatest precipitation mean deviations at tropical 


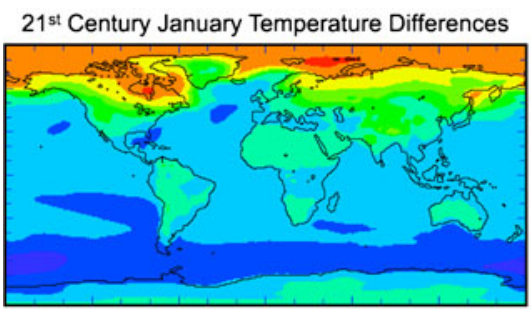

Mean Deviation

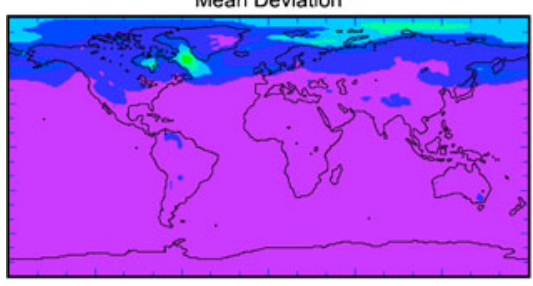

$21^{\text {st }}$ Century January Precipitation Differences

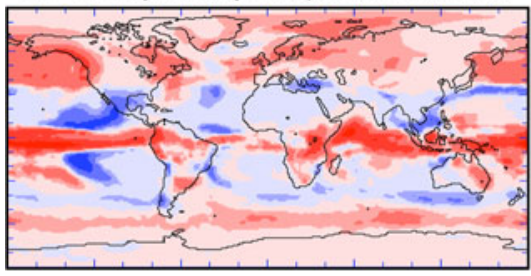

Mean Deviation

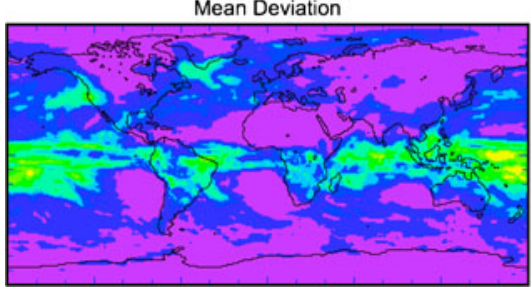

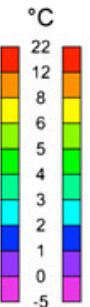

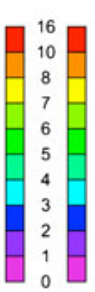

$\mathrm{mm}$
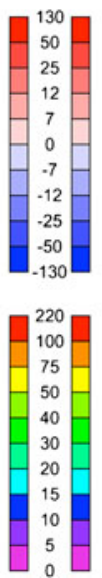

$21^{\text {st }}$ Century July Temperature Differences

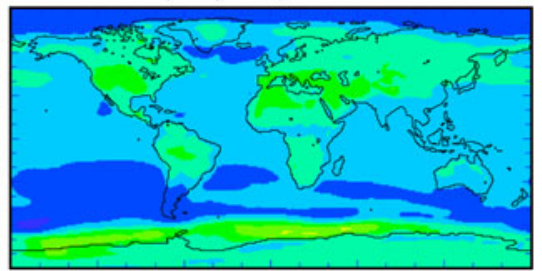

Mean Deviation

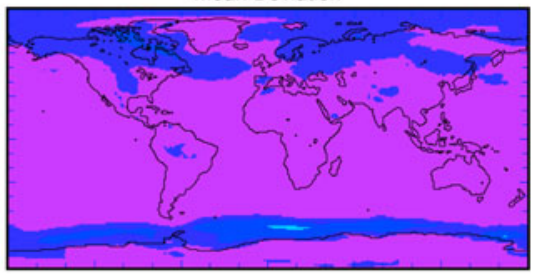

$21^{\text {st }}$ Century July Precipitation Differences
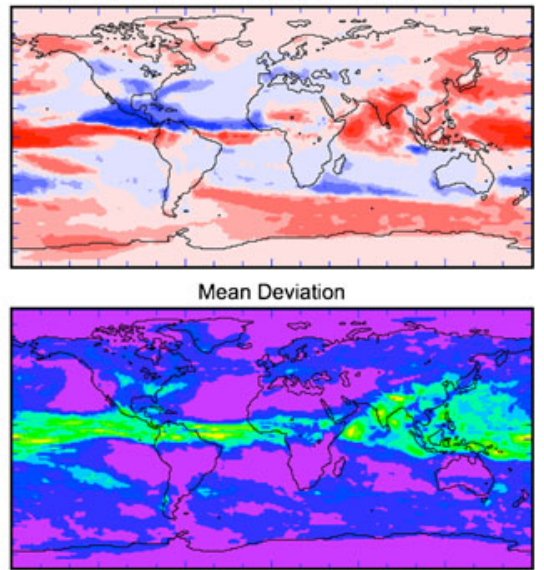

Fig. 4 Twenty-first century three-decade mean (2071-2100) January and July surface temperature and precipitation change (relative to the twentieth century) and mean deviations, averaged across all 10 GCM simulations

latitudes in the region of greatest precipitation associated with the Intertropical Convergence Zone (ITCZ).

Figure 4 shows the January and July 2-m (above the Earth's surface) air temperature differences for the last three decades of the twenty-first century derived from all 10 climate simulations. The greatest degree of warming occurs over the Arctic Ocean during the Northern Hemisphere winter, with temperatures warming as much as $12^{\circ} \mathrm{C}$. The magnitude of the mean deviations is fairly small, with peak deviations of about $5^{\circ} \mathrm{C}$. One remarkable feature of the temperature changes is the almost complete lack of any regions of cooling in the monthly mean climate. This is in dramatic contrast to the heterogeneous patterns of precipitation changes. As can be seen in Fig. 4, although the Earth is generally wetter due to temperature-driven enhanced evaporation, many parts of the world are predicted to be significantly drier, probably mostly due to changes in atmospheric circulation. Much like the twentieth 

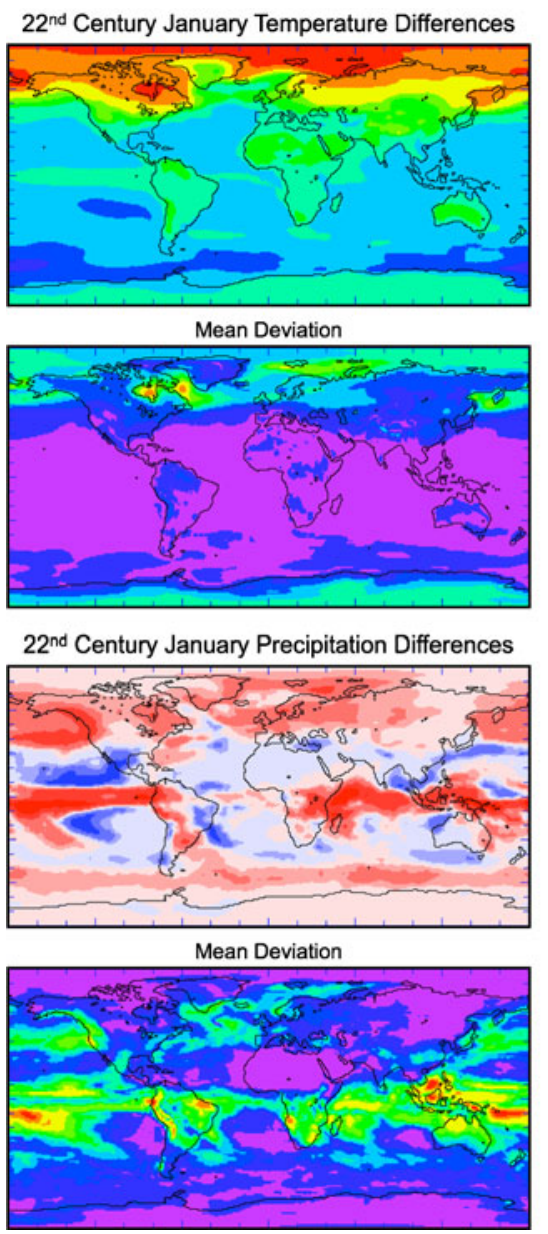
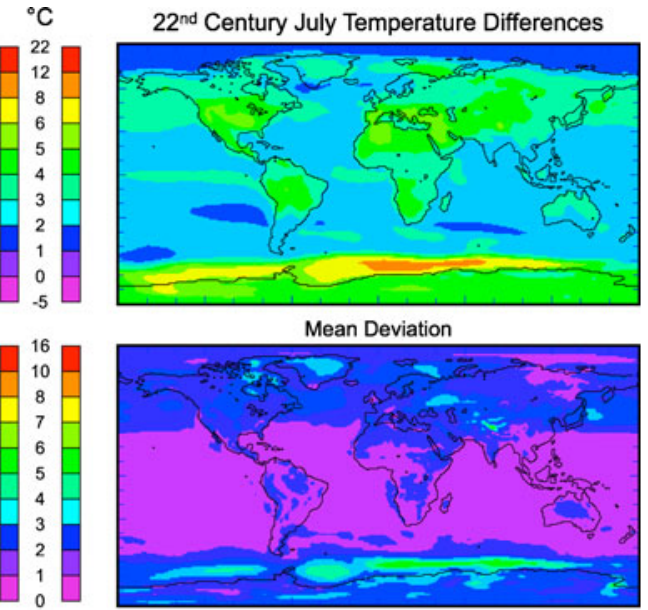

$\mathrm{mm}$
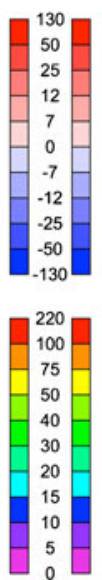

\section{$2^{\text {nd }}$ Century July Precipitation Differences}
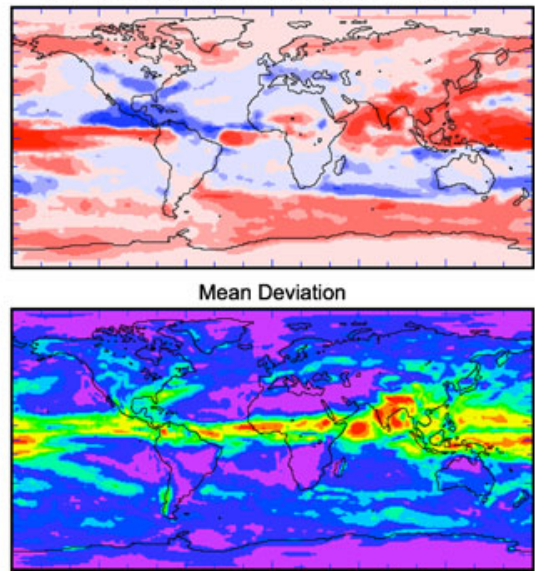

Fig. 5 Twenty-second century three-decade mean (2171-2200) January and July surface temperature and precipitation change (relative to the twentieth century) and mean deviations, averaged across the seven 3-century GCM simulations

century precipitation fields, the regions with the largest climate changes are also the areas where the models diverge the most. In both January and July, tropical areas exhibit monthly total precipitation increases or decreases well over $50 \mathrm{~mm}$ of water but some of these areas also have a mean deviation that exceeds $50 \mathrm{~mm}$ as well. This is probably due to a mostly latitudinal misalignment of the monthly position of the ITCZ across the models.

Figures 5 and 6 display the January and July temperature and precipitation changes (relative to twentieth century conditions) and mean deviations for the three decades that end the twenty-second and twenty-third centuries. These figures show that the high latitude winter warming continues to increase in magnitude despite the constant nature of the $\mathrm{CO}_{2}$ forcing. This is attributable to the thermal inertia of the global oceans within the Oceanic General Circulation Models (OGCMs) in the climate simulations in combination with snow and ice albedo feedbacks that 


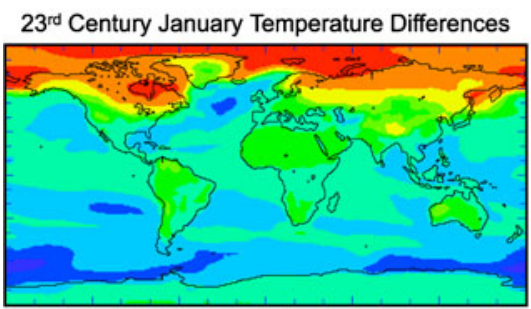

Mean Deviation

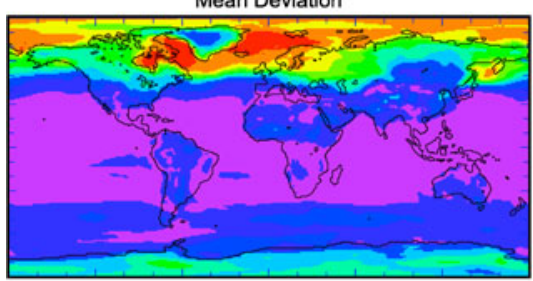

$2^{\text {rd }}$ Century January Precipitation Differences
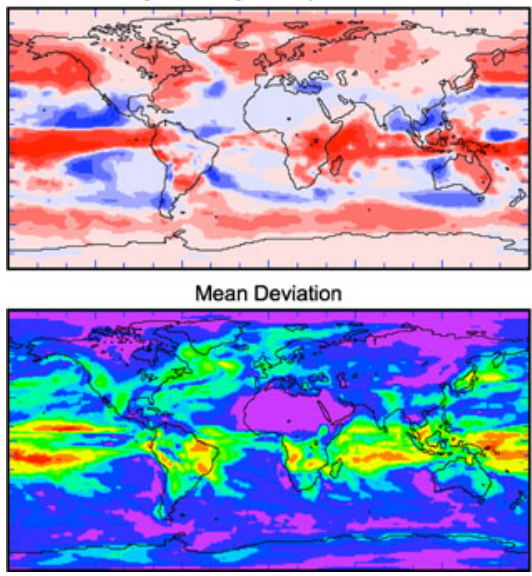
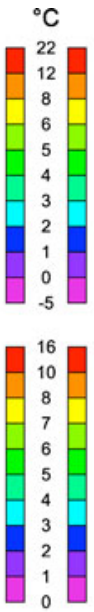

$\mathrm{mm}$
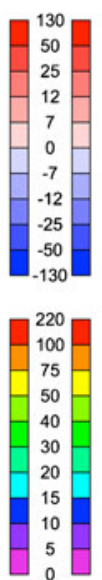

$23^{\text {rd }}$ Century July Temperature Differences

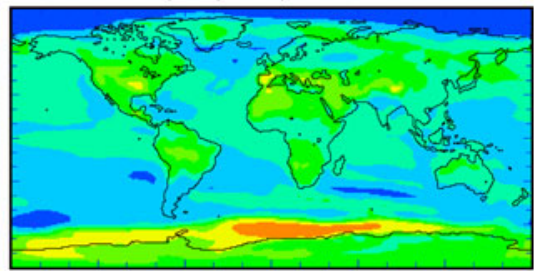

Mean Deviation

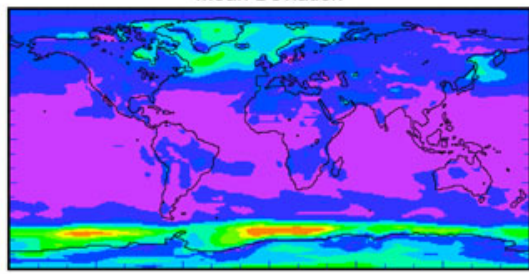

$23^{\text {rd }}$ Century July Precipitation Differences

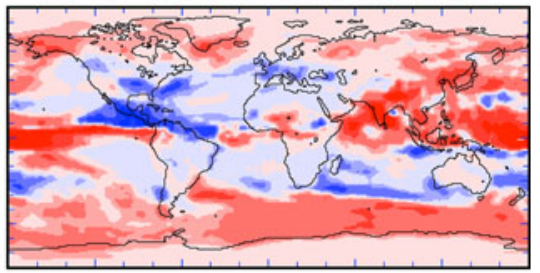

Mean Deviation

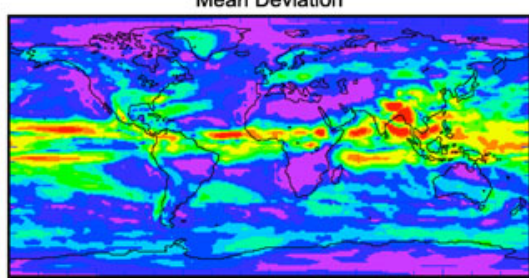

Fig. 6 Twenty-third century three-decade mean (2271-2300) January and July surface temperature and precipitation change (relative to the twentieth century) and mean deviations, averaged across the five 4-century GCM simulations

enhance the high latitude climate signal. A comparison of the intensities of high latitude winter warming at the ends of the twenty-first, twenty-second, and twentythird centuries (Figs. 4, 5 and 6) shows continuing but decelerating warming as the Earth system comes into thermal equilibrium with the IPCC Fourth Assessment SRES A1B doubled- $\mathrm{CO}_{2}$ forcing. Of course, it can also be seen in Fig. 6 that the mean deviation across the five climate simulations that span the twenty-third century becomes quite large in the regions of greatest warming, indicating increasing uncertainties in climate model results.

\subsection{Ecological change}

The upper left-hand panel in Fig. 7 shows the five-biome versions of results from the EVE model driven by the interpolated twentieth century three-decade mean 
Table 1 Climate and ecological sensitivity for the ten climate simulations across three centuries
The average ecological sensitivity values are derived from a single EVE simulation for each century using averaged interpolated climates, not from averaging across the multiple EVE results associated with individual GCMs for each century. The models are sorted from greatest to least climate sensitivity, which has units of degrees Celsius $\left({ }^{\circ} \mathrm{C}\right)$

\begin{tabular}{llll}
\hline Climate model & Sensitivity & ES 1 & ES 2 \\
\hline 21st century & & & \\
MIROCHR & 4.095 & 0.574 & 0.431 \\
MIROCMR & 3.085 & 0.559 & 0.432 \\
CCMAT63 & 3.021 & 0.504 & 0.396 \\
IPSL & 3.020 & 0.493 & 0.398 \\
NCAR & 2.617 & 0.467 & 0.334 \\
CNRM & 2.565 & 0.504 & 0.346 \\
INMCM & 2.534 & 0.496 & 0.355 \\
IAP & 2.409 & 0.410 & 0.307 \\
CCMAT47 & 2.402 & 0.478 & 0.374 \\
MRI & 2.175 & 0.410 & 0.281 \\
Average & 2.792 & 0.490 & 0.365 \\
22nd century & & & \\
MIROCMR & 4.052 & 0.599 & 0.472 \\
CCMAT63 & 3.918 & 0.560 & 0.447 \\
IAP & 3.417 & 0.478 & 0.362 \\
CNRM & 3.293 & 0.575 & 0.399 \\
INMCM & 3.280 & 0.548 & 0.393 \\
CCMAT47 & 3.035 & 0.526 & 0.416 \\
MRI & 2.683 & 0.444 & 0.302 \\
Average & 3.383 & 0.531 & 0.391 \\
23rd century & & & \\
MIROCMR & 4.328 & 0.609 & 0.485 \\
CCMAT63 & 4.235 & 0.575 & 0.460 \\
CNRM & 3.558 & 0.583 & 0.406 \\
CCMAT47 & 3.316 & 0.544 & 0.434 \\
MRI & 2.784 & 0.450 & 0.307 \\
Average & 3.644 & 0.545 & 0.407 \\
\hline
\end{tabular}

monthly climate averaged across all 10 climate simulations. The qualitative degree of agreement between the EVE-simulated twentieth century global vegetation patterns generated using climate data (Fig. 2) and from direct unfiltered GCM climate output (Fig. 7) is very good, especially relative to how divergent a similar comparison would have been only a decade ago.

The other five panels of Fig. 7 show EVE biome changes projected for the end of the twenty-first century in response to a century of climate change averaged from all 10 GCM simulations. Each panel depicts the geographic response of one of five biomes to projected twenty-first century climate change relative to the twentieth century biome distribution shown in the first panel. Comparing pairs of biome change maps reveals the nature of climate change driven potential biome transitions from the twentieth to the twenty-first century. These equilibrium vegetation change predictions reveal some of the areas of greatest ecological change inherent in the first century of IPCC SRES A1B projected climate change.

The largest areas of biome change are, naturally, located in the areas of greatest climate change - the significant winter warming at the high latitudes of the Northern Hemisphere. These areas of greatest change are the northern and southern ecotones (boundaries or transition zones) of the Northern Hemisphere boreal forest. Looking at the upper right-hand and lower left-hand panels of Fig. 7, we can see the northward 

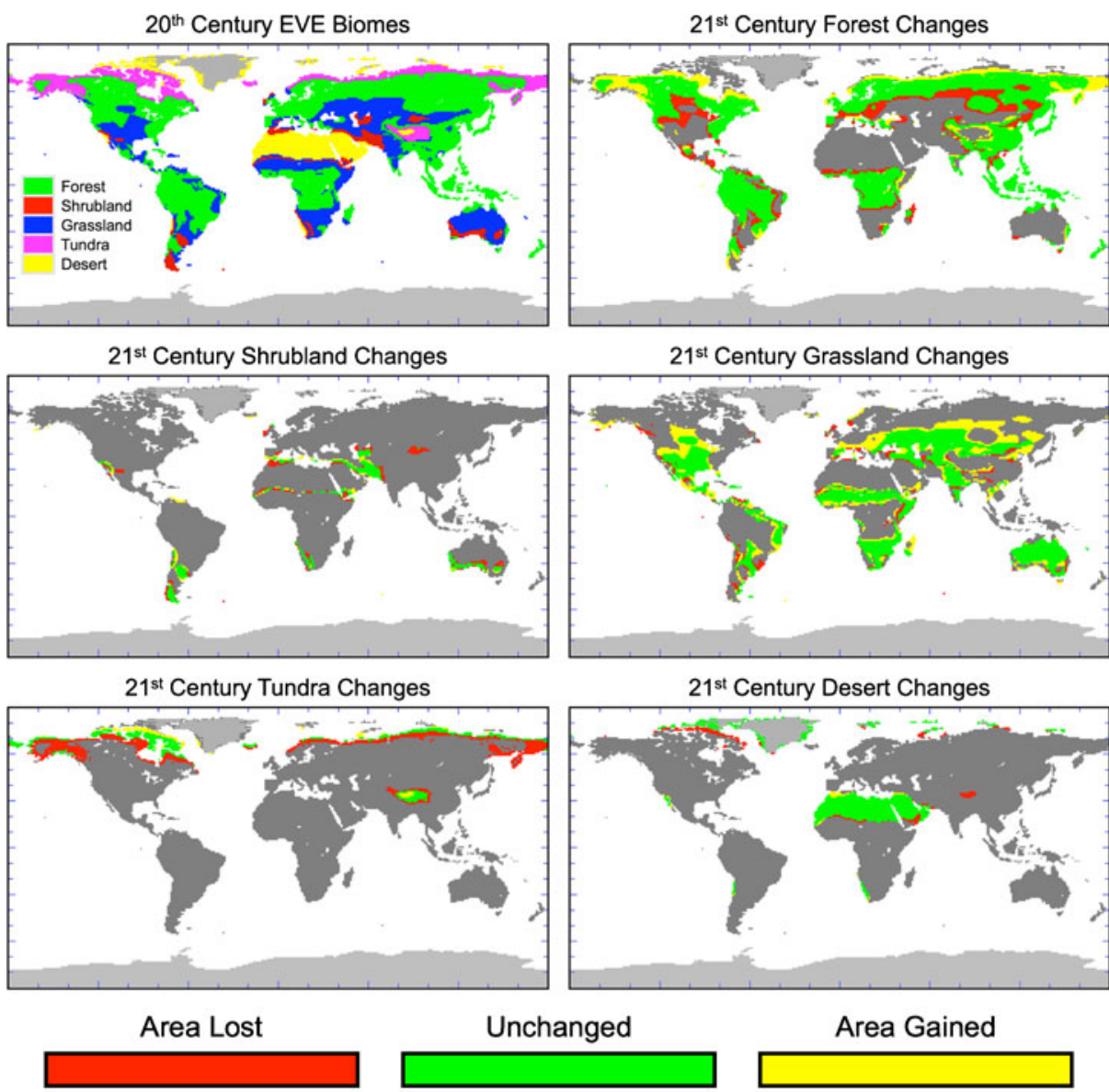

Unchanged

Area Gained

\section{$21^{\text {st }}$ Century Biome Changes}

Fig. 7 Twentieth century EVE biomes and twenty-first century forest, shrubland, grassland, tundra, and desert changes. The twentieth century biome map is derived from three-decade (1971-2000) GCM-averaged climate and uses green for forest, red for shrubland, blue for grassland, magenta for tundra, and yellow for desert. The five twenty-first century maps depict biome changes relative to the twentieth century biome map resulting from a century of IPCC SRES A1B simulated climate change

invasion of tundra regions by the boreal forests of North America and Eurasia. A comparison of the upper and middle right-hand panels reveals the incursion of temperate grasslands into the southern regions of these same boreal forests. In other words, the warming of the Earth, particularly at high latitudes, has caused a general poleward movement of the ecoclimatic niche spaces and associated vegetation types on the Earth's surface.

Looking at the biome changes in greater detail, the low latitude forests are invaded at their edges by grasslands probably due to changes in the water balance, where increased evaporative demand associated with higher temperatures is not entirely matched by increased water availability from enhanced precipitation. Shrublands 
have a very small global area that exhibits a fairly random pattern of gains and losses. Grasslands are somewhat favored by the projected climate change, exhibiting a general expansion, mostly into the previously discussed forested regions. Northern Hemisphere tundra retreats dramatically, being invaded by boreal forest, although it does migrate into polar and Himalayan desert regions. Global tundra area decreases as it migrates into polar areas that are intrinsically smaller due to the spherical geometry of the Earth and as the tundra ecoclimatic niche space migrates into the Arctic Ocean region. Finally, the polar and Himalayan deserts retreat, giving way to tundra, while the Sahara Desert is fairly stable through the projected climate changes.

\subsection{Ecological sensitivity}

The preceding text and figures have highlighted the IPCC SRES A1B monthly mean climate changes and consequent ecological changes characterized by movements of the Earth's five major biomes. Although the response of the EVE model to climate change is geographically continuous at the life form level, it is a fairly daunting task to attempt to analyze and discuss the states and changes in 110 fractional cover maps. After simplifying to a single biome map such as the five-biome maps illustrated above, much of the information has been lost about the degree of plant community change in terms of turnover of the plant species or life forms that make up the biomes. In this study, we apply the two new ecometrics described above in Section 2 of this paper, which we refer to as Ecological Sensitivity metrics 1 and 2, or ES1 and ES2.

Figures 8 and 9 show the level of ecological sensitivity at the end of the twentyfirst century in terms of ES1 and ES2. As a reminder, ES1 represents the percent of the landscape that changes from one life form to another in at least one of the three canopy levels of the EVE model. ES2 measures the same thing, but in terms of major life form changes, such as from a tree to a grass, thus representing a biomescale plant community transition. As can be seen in Fig. 8, most of the Northern Hemisphere boreal forest exhibits a plant community change in $90-100 \%$ of the area of each $1^{\circ} \times 1^{\circ}$ grid cell as simulated by the EVE model in response to predicted twenty-first century climate changes. Many of the boreal forest life forms exist across much of the latitudinal extent of the boreal forest. Therefore, the greatest potential for climate-driven species turnover is at the northern and southern transition zones or ecotones of the boreal forest, with the latitudinal heart of the forest being intrinsically more stable. Consequently, we see in Figs. 8 and 9 a latitudinal dipole in ES1 and ES2, respectively, at both the northern and southern boreal forest ecotones, with 90-100\% change at the peaks, and dramatically lower levels of change across a thin latitudinal strip at the heart of the North American and Eurasian boreal forests. The ES1 map shows the tremendous level of species turnover within the boreal forest, where, for example, one tree species may be invading the area formerly occupied by another tree species. In contrast, the latitudinal peak change ridges at the ecotones of the boreal forest seen for ES2 in Fig. 9 are much narrower, indicating the regions of inter-biome changes. Note the general agreement between the "hotspots" of Fig. 9 and the biome transitions found in Fig. 7.

The mean deviation map of Fig. 8 shows the EVE ES1 results from the 10 climate simulations agreeing to within $20 \%$ for most of the world, with most of the rest of the world being within $20-40 \%$ of the mean ES1 result. The Fig. 9 mean deviation map 


\section{$21^{\text {st }}$ Century Ecological Sensitivity 1}

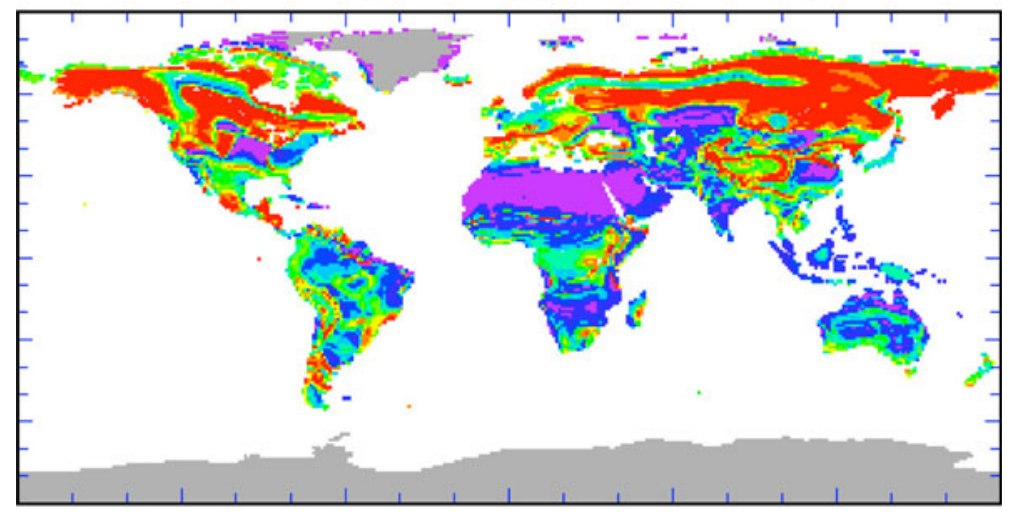

Mean Deviation

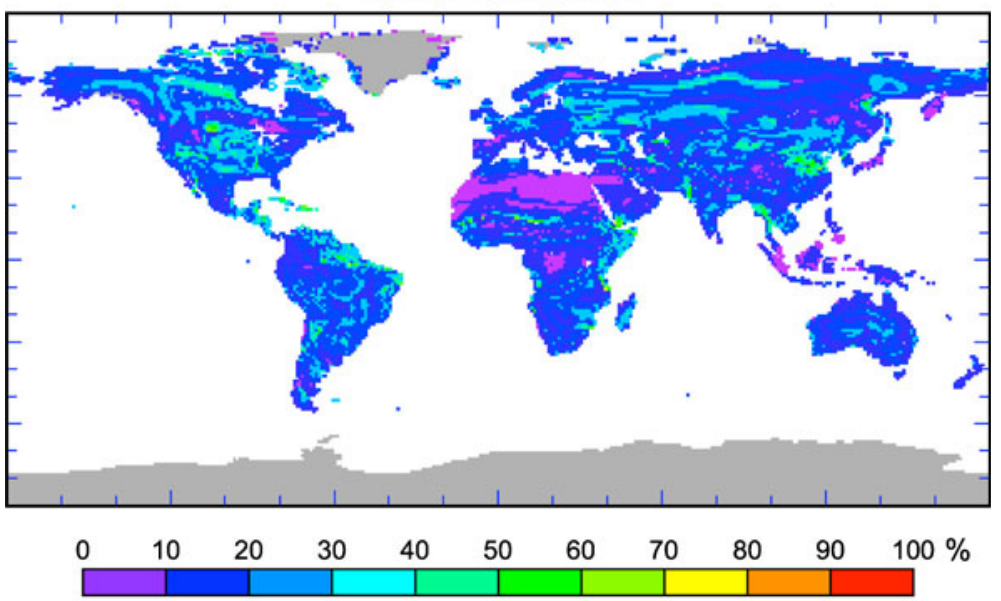

Ecological Sensitivity

Fig. 8 Twenty-first century Ecological Sensitivity 1 and mean deviation derived from the 110 plant life form fractional cover maps generated by EVE from climate change projections averaged across all 10 climate simulations

reveals considerably more disagreement (10-40\% for most of the planet) across the 10 simulations, indicating the greater distance between the ecoclimatic niche spaces of the biome-related groups of life forms in comparison with niche-space distances between individual life forms. Naturally, both mean deviation maps peak in the regions with the greatest degree of plant migrations.

Figure 8 also shows that most of the world's land that is not covered by ice or desert, exhibits at least a 30\% change in landscape cover as estimated by the ES1 map. Other hotspots include areas around the Himalayas and the Tibetan Plateau, eastern equatorial Africa, Madagascar, the Mediterranean region, southern South America, and the Great Lakes and Great Plains areas of North America. This is considerably more alarming for the future health of the Earth's ecosystems than the 


\section{$21^{\text {st }}$ Century Ecological Sensitivity 2}

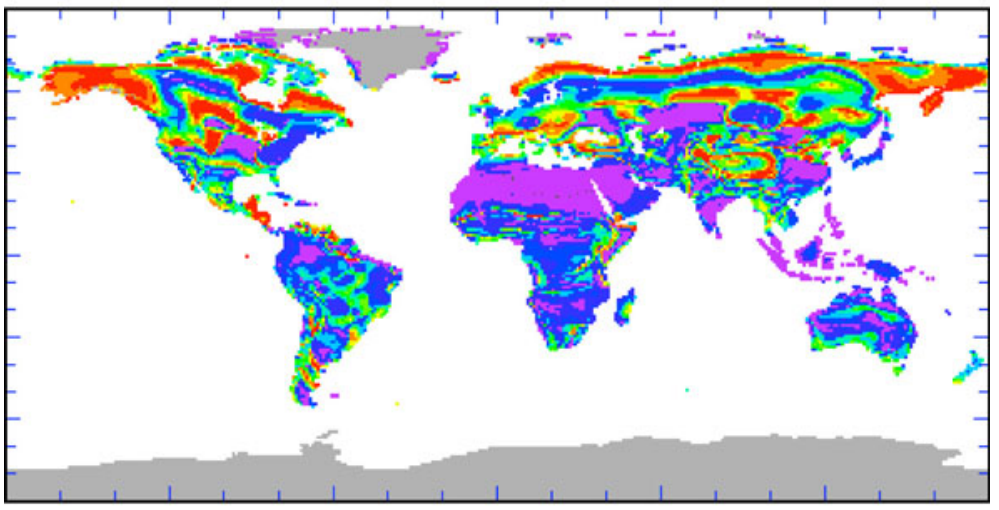

Mean Deviation

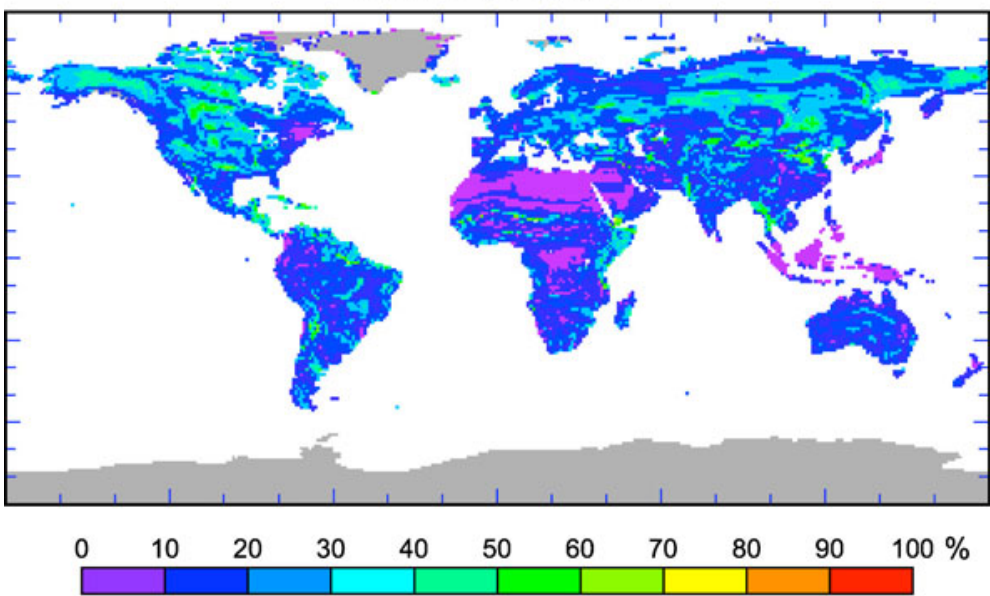

\section{Ecological Sensitivity}

Fig. 9 Twenty-first century Ecological Sensitivity 2 and mean deviation derived from the 110 plant life form fractional cover maps generated by EVE from climate change projections averaged across all 10 climate simulations

much simpler projection provided by the biome change maps. For the twenty-first century ES2 result in Fig. 9, most of the ice-free and desert-free land of the Earth undergoes at least a $20 \%$ potentially biome-changing shift in life-form landscape cover.

Figure 10 shows Ecological Sensitivity 1 and 2 and mean deviation maps for the twenty-second and twenty-third centuries derived from EVE simulations generated from monthly mean climate averaged across the groups of seven 3-century and five 4-century climate simulations. Comparing the ES1 and ES2 results for the twentysecond and twenty-third centuries in Fig. 10 with those for the twenty-first century found in Figs. 8 and 9, it is clear that the bulk of the additional warming (see Figs. 5 and 6) and hence ecological sensitivity response occurs primarily in the first 
$22^{\text {nd }}$ Century Ecological Sensitivity 1

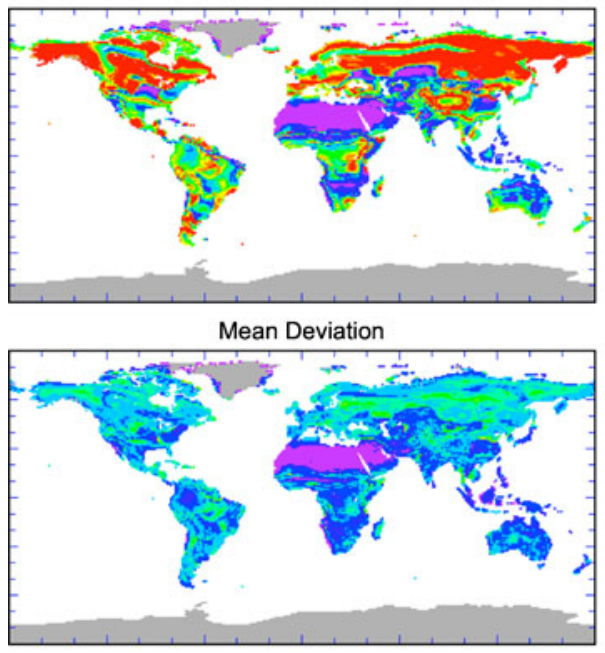

$23^{\text {rd }}$ Century Ecological Sensitivity 1
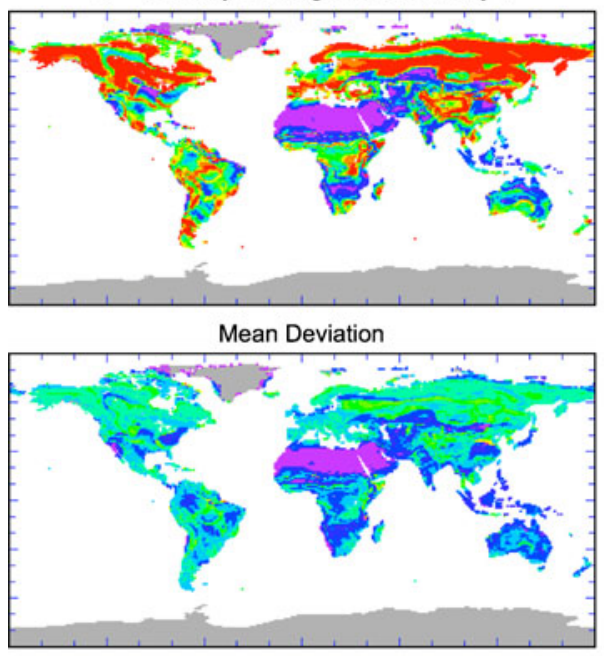

$22^{\text {nd }}$ Century Ecological Sensitivity 2
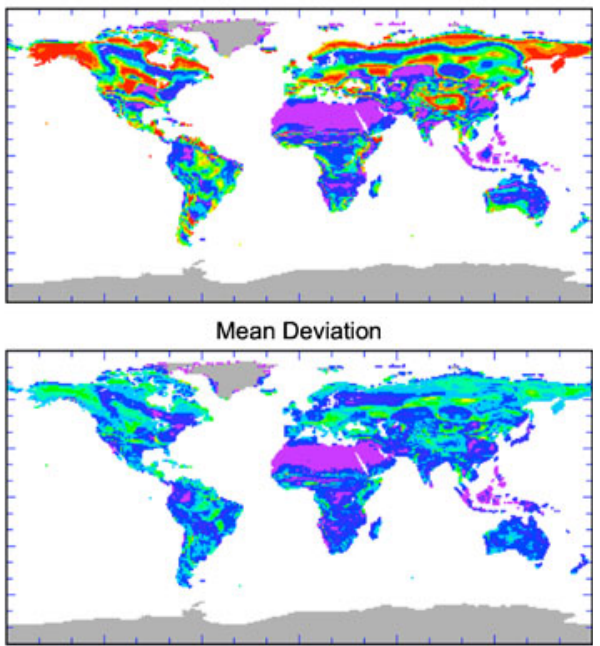

$23^{\text {rd }}$ Century Ecological Sensitivity 2
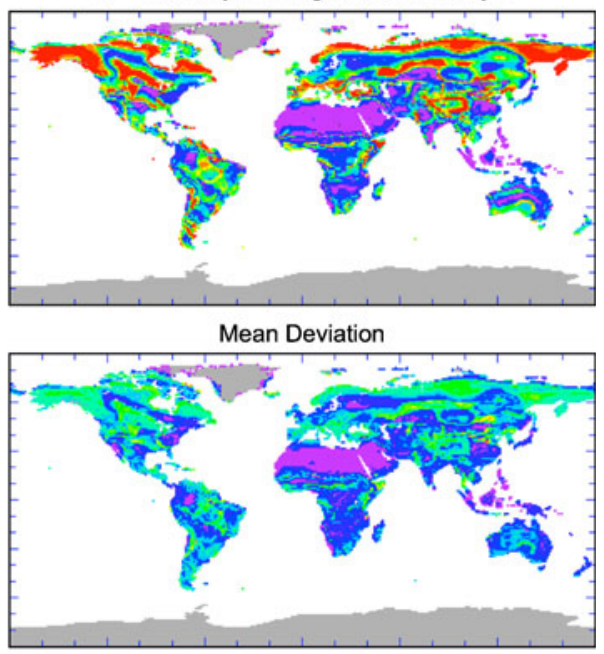

50

$100 \%$

\section{Ecological Sensitivity}

Fig. 10 Twenty-second and twenty-third century Ecological Sensitivity 1 and 2 and mean deviation maps derived from the 110 plant life form fractional cover maps generated by EVE from climate change projections averaged across the groups of seven 3-century and five 4-century climate simulations, respectively. The top half of the figure is the twenty-second century, while the bottom half is the twenty-third century results. The left half of the figure is ES1, while the right half is ES2 results

(the twenty-second) century following the leveling off of atmospheric $\mathrm{CO}_{2}$ in the SRES A1B scenario. This is probably due to the timescales associated with the thermal inertia of the global ocean within the OGCMs. Basically, the ecological 
hotspots, especially those associated with the Northern Hemisphere boreal forest, continue to expand. Additional hotspots open up in tropical regions probably due to misalignments between the heterogeneities of the changes in the availability of water and energy.

\subsection{Globally and seasonally averaged climate sensitivity}

The globally and seasonally averaged climate sensitivities to the $\mathrm{CO}_{2}$ doubling at the end of the twenty-first century range from a warming of 2.2 to $4.1^{\circ} \mathrm{C}$ across the ensemble of 10 climate simulations, with a median sensitivity of $2.6^{\circ} \mathrm{C}$ (Table 1 ). The average global warming of $2.8^{\circ} \mathrm{C}$ is larger than the median value mostly due to the influence of the most sensitive model simulation (MIROCHR), which is an outlier. At the end of the twenty-second century, the seven models exhibit a warming of 2.7 to $4.1^{\circ} \mathrm{C}$, with a median sensitivity of 3.3 and an average sensitivity of $3.4^{\circ} \mathrm{C}$. Although the upper value of the range of projected twenty-second century warming is identical to the upper value for the twenty-first century, this actually represents significant additional warming, as the anomalously sensitive MIROCHR SRES A1B simulation does not include the twenty-second century, and the next warmest simulation (the medium resolution simulation using the same model, MIROCMR) warms an additional $1{ }^{\circ} \mathrm{C}$ in the twenty-second century. The five climate simulations that run to the end of the twenty-third century respond to the $\mathrm{CO}_{2}$ doubling with a warming of 2.8 to $4.3^{\circ} \mathrm{C}$, with a median and an average sensitivity of $3.6^{\circ} \mathrm{C}$.

Focusing on the average values, the transient twenty-first century that spans the period of greenhouse gas buildup exhibits a $2.8^{\circ} \mathrm{C}$ warming, with the twenty-second century contributing an additional $0.6^{\circ} \mathrm{C}$ and the twenty-third century adding another $0.2^{\circ} \mathrm{C}$ to the climate response. In other words, the three centuries result in about $77 \%, 16 \%$, and $7 \%$ of the total three-century warming of $3.6^{\circ} \mathrm{C}$. While the average conditions of the last three decades of the twenty-first century include only $85 \%$ of the greenhouse gas forcing, $77 \%$ of the total projected Earth system temperature rise in the SRES A1B scenario occurs in the first hundred years following the last three decades of the twentieth century.

\subsection{Globally averaged ecological sensitivity}

The globally averaged Ecological Sensitivity 1 (ES1) for the 10 climate simulations at the end of the twenty-first century ranges from $41 \%$ to $57 \%$ of the Earth's vegetated landscape undergoing plant community changes, with a median and an average sensitivity of $49 \%$ (Table 1). The twenty-first century results for Ecological Sensitivity 2 (ES2) range from $28 \%$ to $43 \%$ of the Earth's terrestrial ecosystems undergoing biome-scale changes, with a median and an average sensitivity of $\sim 36.5 \%$. The average ecological sensitivity values in Table 1 are derived from a single EVE simulation for each century using averaged interpolated climates, not from averaging across the multiple EVE results (associated with individual GCMs) for each century. At the end of the twenty-second century, the seven climate and vegetation simulations result in ES1 values from $44 \%$ to $60 \%$, with a median sensitivity of $55 \%$ and an average sensitivity of $53 \%$, and ES2 values from $30 \%$ to $47 \%$, with a median and an average sensitivity of $39 \%$. The five simulations that complete the twenty-third century have ES1 values from $45 \%$ to $61 \%$, with a median sensitivity of $58 \%$ and 
an average sensitivity of $55 \%$, and ES2 values from $31 \%$ to $49 \%$, with a median sensitivity of $43 \%$ and an average sensitivity of $41 \%$.

Focusing again on the average values, from the end of the transient twenty-first century that spans the period of greenhouse gas buildup to the ends of the twentysecond and twenty-third centuries, ES1 transitions from $49 \%$ to $53 \%$ to $55 \%$, while ES2 goes from $37 \%$ to $39 \%$ to $41 \%$ in the ecological response to climate change. In other words, the three centuries result in $90 \%, 7.5 \%$, and $2.5 \%$ of the eventual global ES1 landscape change of $55 \%$; and $90 \%, 6 \%$, and $4 \%$ of the eventual global ES2 plant community change of $41 \%$. So, even though the twenty-first century only exhibits $77 \%$ of the three-century temperature response, $90 \%$ of the total threecentury projected plant community response (as characterized by both ES1 and ES2) to the SRES A1B scenario occurs because of the climate changes that occur during the hundred-year transient period following the twentieth century.

\section{Discussion}

\subsection{Ecological sensitivity as a function of climate sensitivity}

Just as global climate sensitivity is usually defined as the seasonally and globally averaged degree of temperature change in response to a doubling of atmospheric carbon dioxide (equivalent), we define global ecological sensitivity as the globally averaged degree of plant community change driven by the climate change associated with a $\mathrm{CO}_{2}$ doubling. Figure 11 shows Ecological Sensitivities 1 and 2 as a function of climate sensitivity for the 22 century-long segments of the 10 SRES A1B climate simulations.

The median value for ES1 across all of the simulations is about 52\%, while for ES2 it is about $40 \%$. For the five 3-century simulations in Fig. 11, the ES1 curves are all either flat or decreasing in slope. This is not true for the ES2 curves, where two of the simulations (MIROCMR and MRI) actually exhibit small increases in slope, indicating that the quality of the twenty-third century climate change projected by these two models slightly favors larger scale biome-centric life-form responses relative to total life-form responses.

All of the lines generated by the sets of GCM-EVE ecological sensitivity results, if extended back to zero climate change would have positive y-intercepts, indicating that the slopes of these functions must be decelerating, since these curves must actually pass through the origin. This deceleration of ecological sensitivity must be the case, because, although the degree of climate change is somewhat open-ended, the results of simulations using the current formulation of ecological sensitivity (ES1 and ES2) begin to achieve saturation as much of the world approaches $90-100 \%$ change, particularly in the regions of greatest climate sensitivity. Obviously, ES1 and ES2 as functions of climate sensitivity must be approximately asymptotic to $\mathrm{ES}_{\mathrm{i}}=1$.

Ecological sensitivity can be defined relative to a standard climate forcing such as the doubling of carbon dioxide (equivalent) with consequent model-projected climatological changes. An alternative reference frame is to look at ecological sensitivity relative to a certain fixed magnitude of observed or predicted climate change. We can use this alternative viewpoint to look at ecological sensitivity as a function 


\section{Ecological Sensitivity 1}

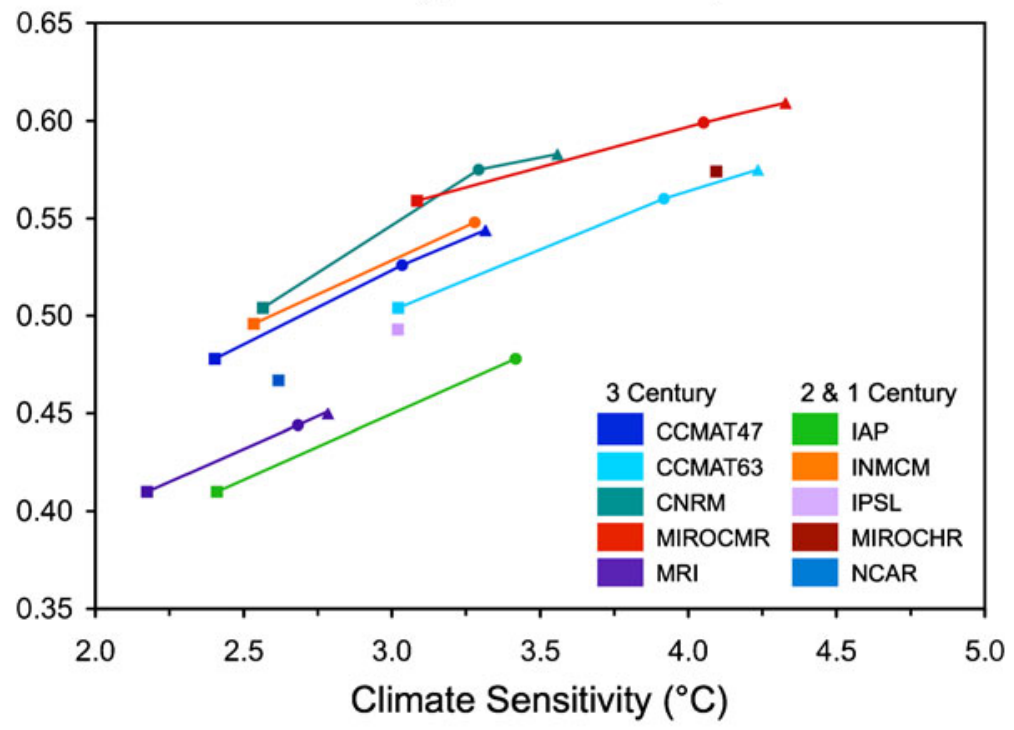

\section{Ecological Sensitivity 2}

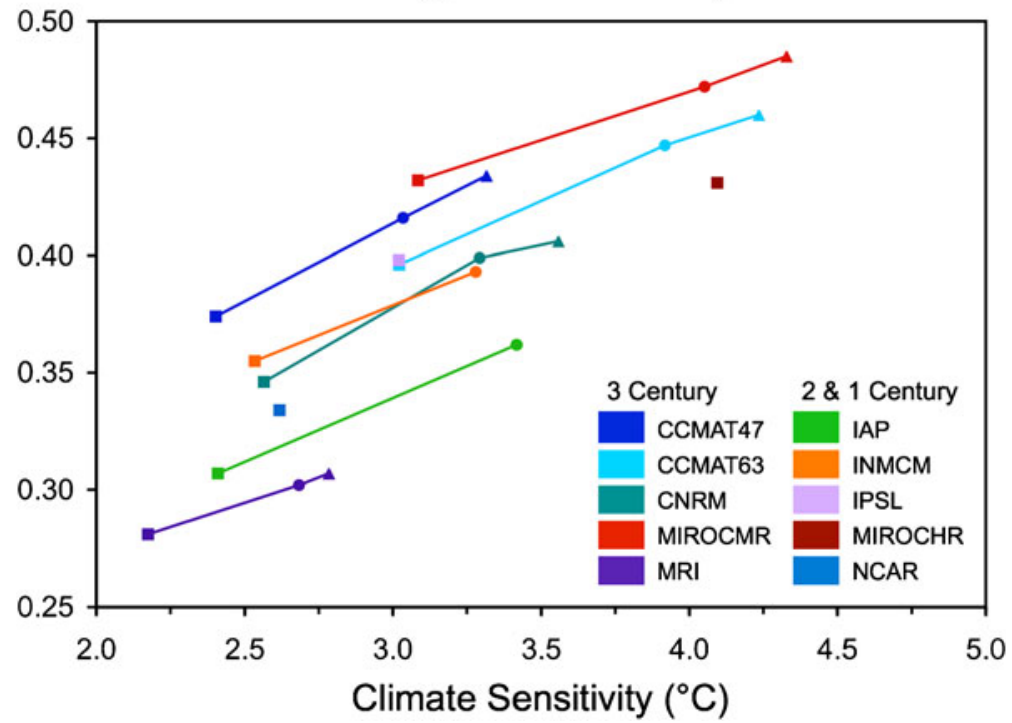

Fig. 11 Ecological Sensitivity 1 and 2 versus climate sensitivity at the end of each of the three centuries. The 10 colors represent the GCM climate simulations, while the three shapes represent the centuries: square $=$ twenty-first century, circle $=$ twenty-second century, and triangle $=$ twentythird century

of climate sensitivity by dividing the average ecological sensitivity by the average climate sensitivity, which is the average magnitude of the ecological response to each degree Celsius of warming. The globally averaged ratios of ecological sensitivity to climate sensitivity at the end of the twenty-first, twenty-second, and twenty-third 
Table 2 ES1 and ES2 ecosensitivity to climate sensitivity ratios (per ${ }^{\circ} \mathrm{C}$ )

\begin{tabular}{|c|c|c|c|c|c|c|}
\hline \multirow[b]{2}{*}{ No. of simulations } & \multicolumn{3}{|c|}{ ES1 / climate sensitivity } & \multicolumn{3}{|c|}{ ES2 / climate sensitivity } \\
\hline & 10 & 7 & 5 & 10 & 7 & 5 \\
\hline 21 st century & 0.176 & 0.183 & 0.182 & 0.131 & 0.134 & 0.135 \\
\hline 22nd century & & 0.157 & 0.157 & & 0.116 & 0.117 \\
\hline $23 r d$ century & & & 0.150 & & & 0.112 \\
\hline
\end{tabular}

centuries can be seen in Table 2, which summarizes the trajectories of the three overlapping groups of simulations across the three experimental centuries. For ES1, all three groups result in $18 \%$ landscape plant community change per ${ }^{\circ} \mathrm{C}$ of warming at the end of the twenty-first century. As the climatological hotspots saturate the ecological response of these regions, the average plant community change per ${ }^{\circ} \mathrm{C}$ naturally lessens somewhat, with the end of the twenty-second century showing $16 \%$ landscape change per ${ }^{\circ} \mathrm{C}$ of warming, and the end of the twenty-third century exhibiting $15 \%$ vegetated area change per ${ }^{\circ} \mathrm{C}$, averaged over two and three centuries, respectively. For ES2, the three groups are also in agreement, with the end of the twenty-first century having an average ecological change of $13 \%$ of the landscape per ${ }^{\circ} \mathrm{C}$ of warming, while by the end of the twenty-second century, the rate of vegetation change is $12 \%$ per ${ }^{\circ} \mathrm{C}$, and at the end of the twenty-third century the rate has diminished to $11 \%$ terrestrial vegetation change per ${ }^{\circ} \mathrm{C}$ of warming, averaged over two and three centuries, respectively.

These results in terms of ecosensitivity per ${ }^{\circ} \mathrm{C}$ of climate sensitivity are very robust across all of the climate simulations for all three centuries. The values stated above are identical regardless of whether we look at the results derived from the EVE simulations using the averaged interpolated climate across all GCMs or whether we average the results for all of the EVE simulations for each climate simulation. In addition, the ecological to climatological sensitivity ratios are very similar across all of the climate simulations, as the mean deviations for the ratios above are all $1 \%$. The regression lines in Fig. 12 vividly show this remarkable consistency in the ratio of ecological to climatological sensitivity for nine of the ten simulations, with one simulation being an outlier. This consistency is not completely unexpected, since the same EVE model was used to translate all of the GCM-predicted climate changes into ecological changes. This result was in no way guaranteed, however, as the heterogeneities of the changes in temperature and precipitation patterns found in the simulated future climates coupled with the nonlinearities in the relationships of climate and vegetation patterns could easily result in vegetation responses that are very different for the same intensity of global average temperature rise. For the set of 22 century-long experimental simulations, the degree of correlation between the magnitude of climate sensitivity and the magnitude of ecological sensitivity is striking.

\subsection{Exploring potential caveats and limitations}

EVE is an equilibrium model, requiring no model time to respond to climate change. In the real world, there are many inertial properties that limit the potential rates of vegetation change: the longevity of trees and their ability to survive in climates not suitable for their successful reproduction, the finite migration rates of vegetation, discontinuities in soil types, maximum rates of seed dispersal, permafrost, and 


\section{$21^{\text {st }}$ Century Ecological Sensitivity 1}

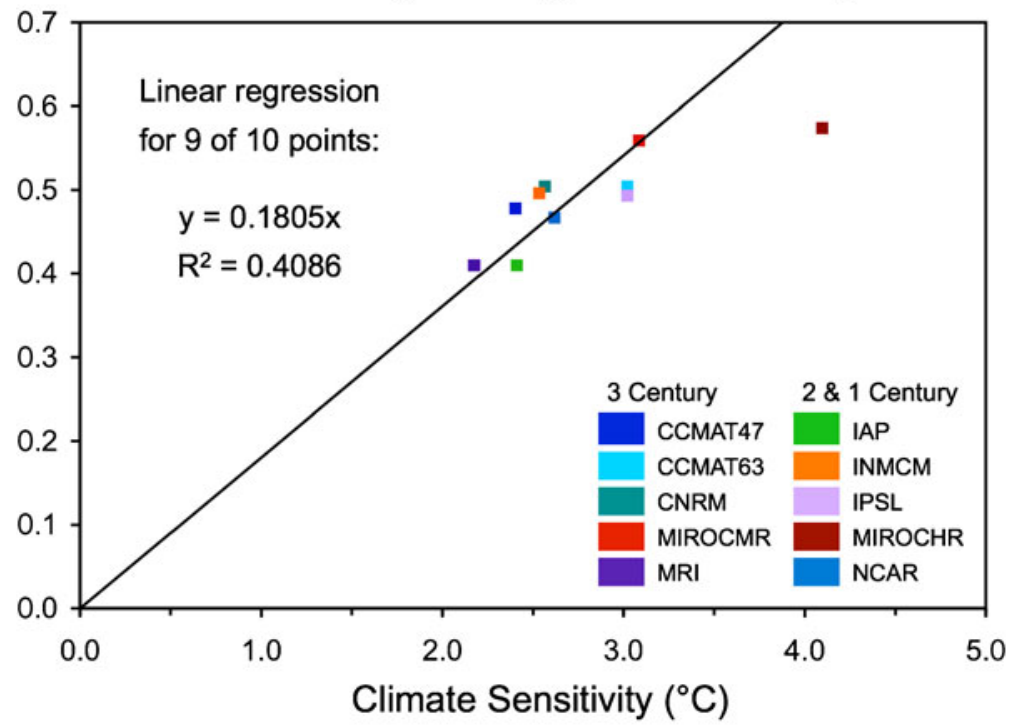

$21^{\text {st }}$ Century Ecological Sensitivity 2

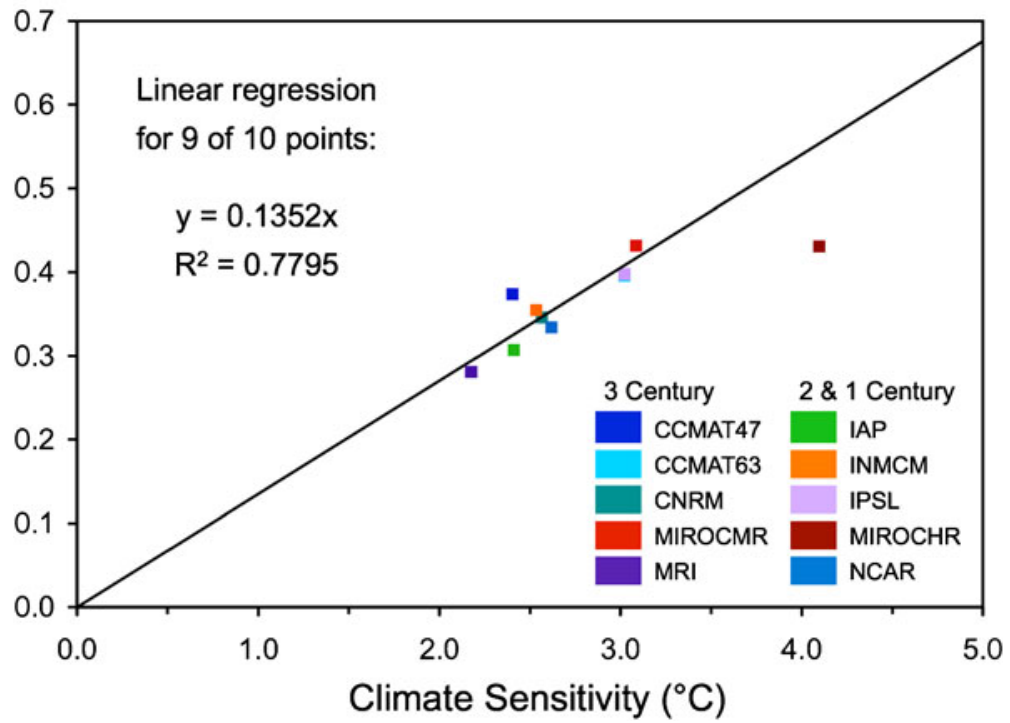

Fig. 12 Ecological Sensitivity 1 and 2 versus climate sensitivity at the end of the twenty-first century. Each graph includes a linear regression line for nine of the 10 simulations

migrational barriers such as agricultural lands, flooded regions, mountain ranges, and urban centers.

EVE's equilibrium nature, as well as its detailed taxonomy, is actually advantageous for ecological sensitivity experiments. While physiologically based ecological models are more suited for simulating the transient nature of atmosphere-biosphere 
interactions, the focus of this study is on the potential level of biospheric transformation contained within a projected degree of climate change. The emphasis here is not the rate of change of the vegetated landscape in response to climate change, but the level of transitional tension between the projected magnitude of climate change and the current state of the vegetation. Our approach is analogous to typical climate change simulations, where a climate model is run to equilibrium following a $\mathrm{CO}_{2}$ doubling. Ecological sensitivity is the intensity of climate change as seen by the biosphere.

The results of this study should be viewed in light of the limitations of the climate and vegetation models used. Although coupled atmosphere-ocean models have progressed substantially over the last three decades, their predictive power is still somewhat limited, as indicated by the magnitudes of the mean deviations in the monthly mean climates derived from the simulations. Much of this is probably due to the limitations and differences in the structural and parameterization attributes of the models in combination with the relatively coarse spatial resolutions of the simulations that do not resolve well many relevant earth system components and processes (e.g., topography, hydrography, convection/clouds). One limitation of this research is the lack of detailed biospheric feedbacks to climate change in most, if not all, of the climate simulations. This can be addressed by interactively coupling a global vegetation model to a GCM (see, for example, Bergengren et al. 2001).

It is important to keep in mind that EVE simulates the natural vegetation that is in equilibrium with a given climate - there are no agricultural regions or other highly disturbed vegetation types within the model. This is not as critical for this study as it could be for coupled experiments exploring biospheric feedbacks (Feddema et al. 2005), and predicting the degree of ecosensitivity for natural vegetation in agricultural regions may only suggest the need to explore adaptive strategies such as planting different crops or increasing irrigation.

As the simulations progress across the four centuries and the number of simulations included goes from 10 to seven to five over the last three centuries, the general level of disagreement estimated in the form of the mean deviation naturally rises, resulting in an increasing portion of the world exhibiting from 40-50\% mean deviation in ES1. This represents an increasing amount of uncertainty in the future climate projections, but does not lessen the degree of warning that the climatological and ecological results represent. Any one of the climate model results taken in isolation exhibits a dramatic level of global-scale plant community changes. The uncertainty pertains more to the geographic patterns of climate and vegetation change, rather than the globally averaged degree of Earth system responses to rising levels of greenhouse gases.

One could argue that the model has three canopy layers and that a species turnover in any one of the layers contributes to the area of vegetation change (although overlapping changes within and between layers are not double-counted), possibly leading to the misperception that areas of $100 \%$ turnover represent a displacement of all of the component plant species in an ecosystem. This is irrelevant, as renormalizing the metric does not affect the gradient, which shows where the Earth's global change hotspots are as seen from the point of view of the terrestrial biosphere. The current formulation of ecosensitivity metrics ES1 and ES2 is designed to give an estimate of the percentage of land area that is being driven to change from one type of vegetation cover to another. If you change one note in a musical 
chord, you have a new chord, and if you change one plant species dominating one ecosystem canopy level for another, you now have a new plant community, with potential consequences for the other plant and animal species in the ecosystem.

\section{Summary and conclusions}

Studies have shown that ecosystems that are exposed to gradual changes in climate can undergo swift and dramatic catastrophic transformations (Scheffer et al. 2001). This highlights the importance of understanding the relationship of ecological sensitivity to climate sensitivity and identifying the regions of the Earth with the greatest degree of ecosensitivity. In this study, we have developed and applied two new ecological sensitivity metrics, analogs of climate sensitivity, to investigate the potential degree of plant community changes over the next three centuries. We have transformed IPCC AR4 projections of climate sensitivity into a biospheric view of climate change as characterized by our two new ecometrics. The predicted equilibrium response of the Earth's terrestrial plant communities to the transient first century of climate change (the twenty-first century) results in $49 \%$ of the Earth's land surface area undergoing plant community changes (ES1) and 37\% of the world's terrestrial ecosystems undergoing biome-scale changes (ES2). Regardless of equilibrium timescales, these new ecometrics highlight the Earth's ecological "hotspots" in response to projected anthropogenic climate changes.

While the global and regional ES1 results for the twenty-first, twenty-second, and twenty-third centuries are indicative of the potential magnitude of disequilibrium and stress in the Earth's terrestrial ecosystems, the ES2 projections show areas that could undergo the most significant changes in plant community composition, requiring even larger adaptive and migrational responses of humans and animals in these regions. When plants are exposed to environmental conditions different from those to which they are adapted, as can occur with climate change, the resulting physiological stress makes the organisms more susceptible to catastrophic damage from ecological disturbances such as disease, insects, and fires. The consequent disruptions to the ecological balance, such as the degradation of available food supplies for animals dependent upon the availability of certain plants, increases the probabilities of local and even regional extinctions. Moreover, landscape or habitat fragmentation-the result of converting much of the Earth's arable land into agricultural zones and urban centers-is reducing the migrational resiliency of plants and animals in their ability to respond to both natural and anthropogenic climate change. Coupled with amplified rates of climate change, synergies could arise that drive losses in biodiversity and require increasing expenditures of human, technological, and capital energy in the employment of mitigation strategies (Hannah et al. 2005; McCarty 2001).

Translating the degree of projected climate change for ten simulations of the IPCC SRES A1B scenario into estimates of ecological sensitivity has shown the importance of mitigation strategies in a new light. The A1B scenario is a "middle path" resulting from a moderate level of governmental, societal, and technological response to the challenges of climate change. Predicted degrees of ecosensitivity indicate the prudence of a robust global response to this challenge such as converting our fossil fuel based economy to one built upon renewable energy resources and 
sustainable positive changes in land use and agricultural practices. The large inertia of the Earth system coupled with the current levels of anthropogenic forcings means that even an aggressive approach to reducing global greenhouse gas emissions will still have to be complemented by adaptive strategies for managing both human and natural systems.

It is somewhat challenging for policymakers and the public to assess the climate changes projected by IPCC scientists, to truly appreciate the implications of a few degrees of global warming. While comparisons with glacial-interglacial climate changes and warnings of melting glaciers, rising sea levels, and other environmental changes are illustrative and important, it is the ecological consequences of all these things that make them vitally important. After all, climate change on a lifeless planet is interesting but not consequential.

Adopting a biospheric view of climate change illuminates the importance of developing intelligent scientific, technological, political, and economic national and global strategies that are based upon the principles of ecology and sustainability and that minimize our greenhouse gas emissions and therefore our impact on climate and life on Earth.

Acknowledgement The research described in this paper was carried out at the Jet Propulsion Laboratory, Caltech, under a contract with NASA.

Open Access This article is distributed under the terms of the Creative Commons Attribution Noncommercial License which permits any noncommercial use, distribution, and reproduction in any medium, provided the original author(s) and source are credited.

\section{References}

Bergengren JC, Thompson SL, Pollard D, DeConto RM (2001) Modeling global climate-vegetation interactions in a doubled $\mathrm{CO}_{2}$ world. Climatic Change 50(1-2):31-75

Box EO (1996) Plant functional types and climate at the global scale. J Veg Sci 7(3):309-320

DeConto RM, Bergengren JC, Hay WW (1998) Modeling Late Cretaceous climate and vegetation. Zentralblatt für Geologie und Paläontologie, Teil I 11(12):1433-1444

DeConto RM et al (1999a) Late Cretaceous climate, vegetation, and ocean interactions. In: Huber B, MacLeod KG, Wing SL (eds) Warm climates in earth history. Cambridge University Press, Cambridge, pp 275-297

DeConto RM, Hay WW, Thompson SL, Bergengren JC (1999b) Late Cretaceous climate and vegetation interactions: the cold continental interior paradox. In: Barrera E, Johnson C (eds) The evolution of cretaceous ocean/climate systems, vol 332. Geological Society of America Special Paper, pp 391-406

Delcourt HR, Delcourt PA, Webb III T (1983) Dynamic plant ecology: the spectrum of vegetation change in time and space. Quat Sci Rev 1:153-175

Feddema $\mathrm{J}$ et al (2005) A comparison of a GCM response to historical anthropogenic land cover change and model sensitivity to uncertainty in present-day land cover representations. Clim Dyn 25(6):581-609

Hannah L, Lovejoy T, Schneider S (2005) Biodiversity and climate change in context. In: Lovejoy T, Hannah L (eds) Climate change and biodiversity, pp 3-14

Hansen J, Sato M, Ruedy R, Lacis A, Oinas V (2000) Global warming in the twenty-first century: an alternative scenario. Proc Natl Acad Sci 97(18):10304-10306

IPCC (2007) Climate change 2007: the physical science basis. IPCC Secretariat, Geneva

Lovejoy T, Hannah L (2005) Climate change and biodiversity. Yale University Press, New Haven

McCarty J (2001) Ecological consequences of recent climate change. Conserv Biol 15(2):320-331 
Pollard D, Bergengren JC, Stillwell-Soller LM, Felzer B, Thompson SL (1998) Climate simulations for 10000 and 6000 years BP using the GENESIS global climate model. Palaeoclimat Data Model 2(2):183-218

Sala OE et al (2000) Global biodiversity scenarios for the year 2100. Science 287(5459):1770-4

Scheffer M, Carpenter S, Foley JA, Folke C, Walker B (2001) Catastrophic shifts in ecosystems. Nature 413(6856):591-596

Schneider SH (2001) What is 'dangerous' climate change? Nature 411:17-19

Schneider SH (2004) The discovery of global warming. Nature 427(6971):197-198

Senior CA, Mitchell JFB (2000) Time-dependence of climate sensitivity. Geophys Res Lett 27(17):2685-2688

Thomas CD et al (2004) Extinction risk from climate change. Nature 427(6970):145-148

Washington WM, Meehl GA (1989) Climate sensitivity due to increased $\mathrm{CO}_{2}$ : experiments with a coupled atmosphere and ocean general circulation model. Clim Dyn 4(1):1-38 